\title{
A systematic method of countermeasure for environmental conservation to harmonize hydro-power development with natural environments
}

\author{
T. Komatsu ${ }^{1} \&$ Y. Yasuda ${ }^{2}$ \\ ${ }^{1}$ J-Power Design Co. Ltd, Japan \\ ${ }^{2}$ College of Science and Technology, Nihon University, Japan
}

\begin{abstract}
This paper presents a systematic method of countermeasure for environmental conservation to harmonize natural environments with hydro-power development based on two hydro-power construction in which Komatsu conducted directly as a project management in Japan.

Since the 1990s, Sustainable Development was required in United Nation Conference on Environment and Development (the Earth Summit) as a commitment.

In the construction of Okinawa pilot seawater pumped-storage power plant, and expanding construction for Okutadami and Otori hydro-power developments, project areas were located in biodiversity such as where precious endangered animals and birds have inhabited. Therefore, various countermeasures for environmental conservation in natural environments were proposed in order to harmonize construction of hydro-power development with natural environments. The proposed managements were systematically conducted by integrating the following measures:

- Basic-countermeasure: design and countermeasure of preventive conservation for precious animals before the construction;

- Countermeasure for hardware activities: field investigation for analyzing natural phenomenon, application of adaptive management in consideration of the conservation for precious animals, replanting in modified grounds based on natural resilience;
\end{abstract}


- Countermeasure for software activities: communication with the persons concerned in project, educational activities for the construction workers, daily patrols for environmental conservation;

- Eco-site monitoring: monitoring for precious understanding of the circumstances in construction area.

Keywords: hydro-power development, biodiversity, coexistence with nature, natural environmental conservation measure, resilience, adaptive management.

\section{Introduction}

Since 2011, electrical generation capacity in the world was $5,460,000,000 \mathrm{~kW}$ including $995,000,000 \mathrm{~kW}$ as hydro-power, $18 \%$ of the total [1]. In the case of Japan, 48,000,000 kW as hydro-power was $17 \%$ of the total $282,000,000 \mathrm{~kW}$ [2]. About 130 years, hydro-power has been operated as a national energy produce on the basis of the energy policy of national government, and national life has been supported.

Generally, hydro-power development affects natural environments because of the installation of the power plant in mountain areas. In a first stage of hydraulic generation, as small scale run-off type power plant was applied, the damage due to the construction to the natural environment was minimized. On the other hand, the large-scale hydro-power development including the dam type was promoted, and the influence on natural environments was not negligible. The influence on natural environment in a sustainable development for hydro-power plant must be clarified, because hydro-power developments should be recommended as clean renewable natural energy that emits no carbon dioxide. In United Nation Conference on Environment and Development (the Earth Summit in 1992) as commitment, a countermeasure of natural environment conservation in the hydropower development has been proposed as environmental policy in Japan in order to accomplish a harmony between the development and natural environments.

The paper presents a systematic method for environmental conservation measures in order to provide technical solutions harmony hydro-power development with nature two projects, Okinawa pilot seawater pumped-storage power plant construction project [3] and Okutadami-Otori hydro-power plants expansion construction project [4].

\section{Okinawa pilot seawater pumped-storage power plant construction project}

Electric Power Development Co. Ltd. (J-POWER) constructed the world's first pilot seawater pumped-storage power plant funded by the Ministry of Trade and Industry (i.e. Ministry of Economy, Trade and Industry) at a northern part of the Mainland Okinawa (Yambaru) from 1990 to 1998, and the plant has been conducted practically after demonstrations for 5 years since 1998 .

In the plant, an upper pond is located on $150 \mathrm{~m}$ above sea level, and is $600 \mathrm{~m}$ upstream from the coast of the Pacific Ocean, which is utilized as a lower pond. 
The upper pond is $25 \mathrm{~m}$ deep and $252 \mathrm{~m}$ wide and has an octagonal shape. The plant generates a maximum of $30,000 \mathrm{~kW}$ of electricity, with a maximum discharge and effective sea water head of $26 \mathrm{~m}^{3} / \mathrm{s}$ and $136 \mathrm{~m}$, respectively. Figure 1 shows a whole view of the plant.

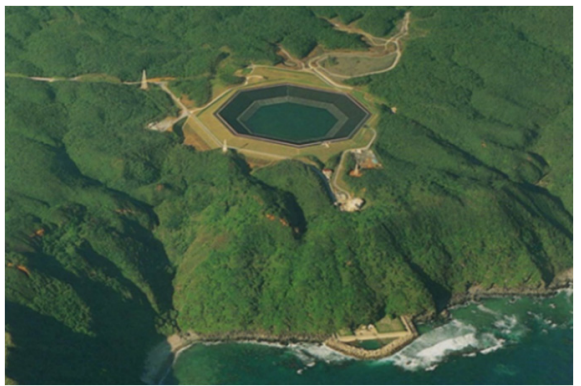

Figure 1: Entire plant view.

\subsection{Natural environmental challenges}

Yambaru in Okinawa is covered with typical forests of subtropical zones (see Figure 2), and is rich regions with biodiversity, which can preserve habitat of biologically important animals, in which belong both endemic species and subspecies. In the construction region, 16 kinds of precious animals such as endangered species (e.g. sapheopipo noguchii (Okinawa woodpeckers), and Gallirallus okinawae (Okinawa rails)) have been confirmed (see Figure 3). Also, a thick layer of reddish soil, which might have a potential for giving damages to corals in the sea behind the project area, was distributed.

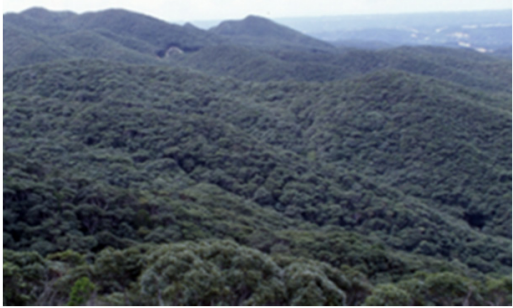

Figure 2: Forests of Yambaru.

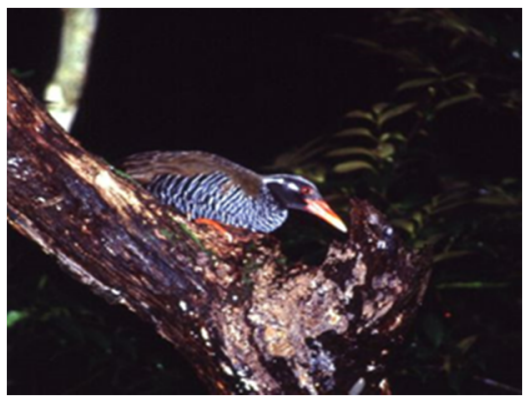

Figure 3: Okinawa rails.

In the construction region in rich regions with biodiversity, the following environmental measures should be required: 1) conservation of biodiversity; 2) prevention against outflows of reddish soil; 3) restoration of constructed area based on natural environment after the construction. As there was no information on these activities in Okinawa Yambaru, original countermeasures must be conducted with persons who have experts' knowledge. 


\subsection{Environmental countermeasures in Yambaru}

\subsubsection{Conservation of biodiversity}

2.2.1.1 Countermeasures before construction In order to conserve biodiversity in the construction region, the following countermeasures were conducted before the construction: (1) the monitoring and the survey for the kind of fauna and flora, their census, and their behavior patterns; (2) the evaluation of the measured data (these activities are called "Eco-site monitoring").

The countermeasures for preventive conservation are summarized as follows:

- Design stage: In order to minimize the effect of construction on natural environments in land and coast, the optimization of constructed area and structures (location, configuration, and dimensions) was designed.

- Conservation for precious animals: Most of precious animals in the construction region are small animals, and countermeasures were conducted in order that they move out from the construction region by themselves. In the case of animals which have a low locomotive, such as frogs, displacement test was conducted. They provide protection against construction by moving them artificially. By considering the defense against invasion of precious animals such as land turtles and frogs into the construction area, polyethylene fences of $30 \mathrm{~cm}$ high were installed for over $8 \mathrm{~km}$ around the construction region, so that small animals could not enter the construction site (see Figure 4). Furthermore, for a little invasion of precious animals into the construction area, gutters with one side slope toward mountainside helping the migration of dropped small animals were installed (see Figure 5). In order that construction workers could judge conservation method appropriately, a pocket-size handbook including both pictures of precious animals and characteristics of their actions were provided.

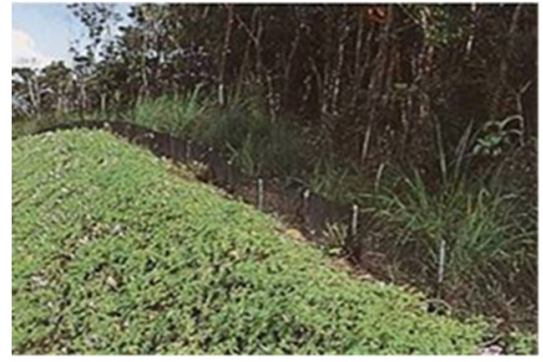

Figure 4: Preventive fence.

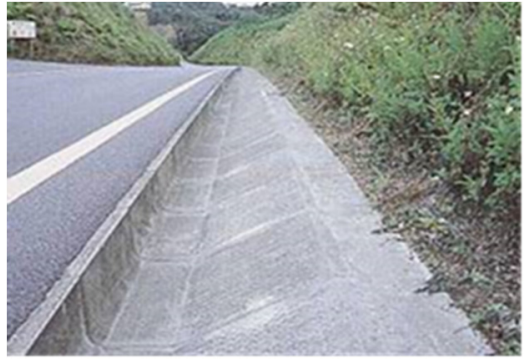

Figure 5: Trapezoid-shaped gutter.

2.2.1.2 Countermeasures during construction Sustainable monitoring: The Eco-site monitoring covering land animals (amphibian and reptile), soil organisms, birds and aquatic life (corals) was periodically conducted every year from 1990 to 1998. Also, any potential negative impacts identified by fixed point and line- 
census monitoring were given a prompt evaluation for implementation of remedial actions.

- Environmental education: Education seminar by persons who have experts' knowledge about animals' cries and behaviors were conducted periodically. The education raised the recognition of construction workers toward environmental preservation. The persons in charge about the natural environmental preservation were selected in the construction workers, and daily patrol was conducted. The repair and improvement in prevention facilities were carried out on the basis of the educational system.

2.2.1.3 Countermeasures after construction The demonstration tests for the plant were conducted for five years after the construction. Eco-site monitoring about eco-system of animals including land animals (insects, mammals), vegetation, marine plants and animals (intertidal zone plants and bottom plants) was conducted in order to investigate the effect of the installation of the seawater pumped-storage power plant on natural environment. The monitoring and the evaluation for 17 years in the world's first seawater pumped-storage power plant project supported that the biodiversity could be preserved in the developed region $[5]$.

\subsubsection{Reddish soil runoff prevention}

2.2.2.1 Countermeasures before construction Drainage trenches with $1.4 \mathrm{~km}$ long were installed along a soil disposal area in order to decrease the volume of reddish soils transported by running water from forests after heavy rain. A sedimentation pond was constructed in order to storage muddy water with reddish soils. The transported volume of reddish soils was estimated as $73,000 \mathrm{~m}^{3}$ by the rainfall of 20 years probability during the construction period, and the storage pond of $46,000 \mathrm{~m}^{3}$ was provided accordingly. The upper pond of the plant was served as a temporary storage, and the volume of $23,000 \mathrm{~m}^{3}$ was utilized in the pond. Also, Chemical treatment plant was installed, and the facilities had a maximum capacity of $200 \mathrm{~m}^{3} / \mathrm{h}$. In order to prevent muddy water from overflowing into the sea, five weirs made of stone were installed.

2.2.2.2 Countermeasures during construction In order to control muddy water with reddish soils during rainfalls, a greening (method by blowing seeds, lawn, and etc.) was conducted immediately soon in the area where the construction for excavation was finished. When bare land was temporarily formed, the surfaces were covered by asphalt emulsion. As an emergency countermeasure, vinyl sheeting was utilized on surfaces. Muddy water stored temporarily in the storage pond (i.e. sedimentation pond) was treated by the chemical treatment plant, and treated water was discharged to the neighboring swamp afterward. During rainfalls, countermeasure for reddish soil runoff prevention was checked by patrols at the construction area and the coastal front. From this confirmation, muddy water effluxes due to construction could not be found at sea along the construction area. 
This project was highly evaluated by the local administration, and high commendation was awarded.

\subsubsection{Restoration of natural environment}

2.2.3.1 Countermeasures before restoration At a later half of construction period, the restoration work was started, and habitat area for wild animals was reproduced in the soil disposal areas of $45,000 \mathrm{~m}^{2}$. There was no experience about the substantial restoration of forests in subtropical zones of Japan. In this project, root taking, planting density, and covering material were tested for 2.5 years by using domestic species. In afforesting plan at the restoration area, the species of trees and the arrangement of the tree planting were decided on the basis of the test results and the succession of forests. In the land creation, ups and downs topography, several kinds of ponds, and nature like creek were designed by considering habits of animals.

2.2.3.2 Countermeasures during restoration For planting density in restoration area, $1.5 \mathrm{~m}^{2}$ area was kept for each planted tree, and mulching was applied for prevention of both soil drying and muddy water effluxes. In the restoration area, the natural resilience was utilized, and as an early restoration, the following activities were conducted: (1) reddish soil amelioration, (2) repairing of mulching, (3) supplemental planting, and (4) pest control.

2.2.3.3 Countermeasures after restoration Periodical monitoring of animals and plants was conducted for five years after the construction, and the suitable restoration, in which the biodiversity could be preserved in the developed region, was confirmed from their habitation and population, animal appearance frequencies, and the rate of growth of trees [5].

\subsubsection{Essential points for harmony of the development with natural environment}

In the seawater pumped-storage power plant project conducted by considering harmony of the development with natural environment, main points can be summarized as follows:

\subsubsection{Conservation for precious animals}

1) Countermeasures for preventive conservation: displacement tests, installation of the intrusion prevention fences, and trapezoidal gutters.

2) Environmental education: The persons in charge about the natural environmental preservation were selected in the construction workers, and daily patrol was conducted as software-countermeasures.

3) Eco-site monitoring about eco-system of animals was conducted in order to investigate the effect of the installation of the seawater pumped-storage power plant on natural environment. The monitoring and the evaluation for 17 years in the world's first seawater pumped-storage power plant project supported that the biodiversity could be preserved in the developed region. 


\subsubsection{Prevention of muddy water effluxes due to construction}

1) Engineering and systematic approaches: Reduction of muddy water effluxes with reddish soil, estimation of muddy water generation, construction of storage pond (i.e. sedimentation pond), and installation of runoff prevention weirs.

2) The persons in charge about the natural environmental preservation were selected in the construction workers, and daily patrol was conducted.

\subsubsection{Restoration of natural environment}

1) Test planting to evaluate natural property.

2) Application of the succession of forests and natural resilience.

3) Eco-site monitoring and evaluation for both construction and restoration processes.

\section{Okutadami and Otori hydro-power expansion construction project}

The expansion project involved two existing hydro-power stations of the JPOWER along the Tadami river in Aganogawa river basin, Okutadami powerstation with $360,000 \mathrm{~kW}$ generation ( $30 \mathrm{~km}$ downstream from the starting point of Tadami River) and Otori power-station with $95,000 \mathrm{~kW}$ generation (9 km downstream from the Okutadami power-station). The project aims to make power generation increase by $287,000 \mathrm{~kW}$. The survey for the project began in 1993 with a simultaneous starting for the environmental conservation measures in the restoration area. The construction was started in July 1999, and finished in June 2003. Immediately after the construction, the hydro-power stations were operated.

Okutadami power-station made further increase of $200,000 \mathrm{~kW}$. In this case, a maximum discharge and an effective water head reached $138 \mathrm{~m}^{3} / \mathrm{s}$ and $164.2 \mathrm{~m}$, respectively. A further intake was installed in Okutadami-dam (see Figure 6), and the following facilities were constructed: a penstock pipe route, an underground power-house, a tailrace tunnel, and an outlet. In the case of Otori hydro-power station, a maximum discharge and effective water head reached $207 \mathrm{~m}^{3} / \mathrm{s}$ and 48.1 $\mathrm{m}$, respectively. Because, the discharge from the Okutadami increased in this project, and $87,000 \mathrm{~kW}$ could be generated. The structures added for power increase consists of an intake, a penstock, underground power-house, a tailrace tunnel, and an outlet.

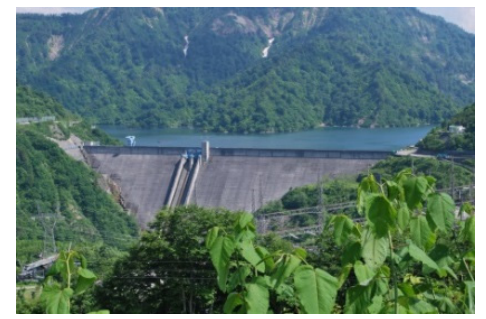

Figure 6: Okutadami-dam. 


\subsection{Environmental challenges in construction region}

Okutadami has a rich region where biodiversity can be preserved, and there are several kinds of habitats for golden eagles and mountain hawk-eagles which are appointed as endangered species IB in the "Red List in Japan", and other precious birds. There were two pairs of golden eagles near the construction region, and one of the pair bred twice and young birds left the nest during four years of the construction period.

Accordingly, environmental challenges in the construction region required as follows:

1) Symbiosis with birds of prey, specifically preservation of young golden eagles (see Figure 7).

2) Sustainable development of the project in which biodiversity could be preserved.

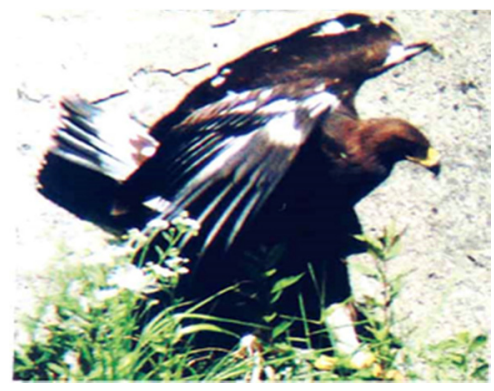

Figure 7: Young golden eagle.

\subsubsection{Countermeasures for preservation of golden eagle}

3.1.1.1 Countermeasures before construction The monitoring and survey in the construction region for 6 years revealed nesting site of the two pairs, behavioral ranges, daily patterns of activity, and breeding condition. As a guideline during the construction period, the following countermeasures were proposed:

1) The ground construction and the utilization of traffic roads for the construction were prohibited during breeding period, November to June, in a circle region with $1.2 \mathrm{~km}$ radius from the nest.

2) In the construction region, the following design was recommended; underground type structures, effective utilization of the existing facilities, and installation of temporary construction facilities outside of a circle region with $1.2 \mathrm{~km}$ radius from the nest.

\subsubsection{Countermeasures during construction}

1) For the conservation in the habitat area of golden eagles, the countermeasure against noise and vibration due to blasting and construction vehicles, arrangement of color used in the construction, and water quality control were conducted. 
2) During growth period for young birds in the nest, periodical patrol was conducted in order to defend biotope of golden eagles against photography act and the invasion of jungle crows. Also, environmental education was applied to the construction workers to heighten a consciousness of environment preservation and to promote their activities of environment preservation.

3) As the flight ability of the young bird is low, the adaptive management program to balance construction with the protection of the young bird was conducted until young birds of golden eagles left the nest [6].

4) Environmental communications for construction-related people such as administration, a protection group, and the citizen were conducted proactively by transmitting information on the golden eagle breeding situation and countermeasures through Home Page and news media.

5) Eco-site monitoring was conducted periodically, and the effect of the construction on the environment preservation was checked. Also, the breeding situation of golden eagle was confirmed. The monitoring data were analyzed precisely through the adaptive management program, and the preservation of young bird was conducted.

\subsubsection{Sustainable management for environmental measures}

Sustainable management program was conducted as follows:

\subsubsection{Activity before construction}

1) The experiments in a water tank were conducted in order to propose the method not to mislead migrated fish (e.g. pond smelt inhabits in Okutadami Lake) into the second intake.

2) The environmental management system was established to conduct systematically the conservation of natural environment including the preservation of golden eagle in the Okutadami areas.

\subsubsection{Activity during construction}

1) The lights and speakers were installed around the second intake not to mislead migrated pond smelt into the intake.

2) Preservations of dragonfly of the precious kind and water plant habitats were conducted in planned soil disposal area. In this area, there were damp grounds before construction. As a countermeasure for the preservation, a marsh was reconstructed for both transplantation of the plants and habitat of the dragonfly in the same area.

3) The construction by-products were effectively utilized as re-resources of both soil materials for tree planting and impervious materials for protecting the creation pond.

4) In construction site, ISO14001 was executed as a first establish in Japan. The environmental conservation measure was systematically conducted by all of the construction workers.

5) The communication system was conducted as follows: (a) The environmental conservation committee was established, and was covered by persons 
concerned in the construction project. (b) The construction process and the activities for the environmental measure were informed periodically through Home Page produced by the construction management office. (c) The report on the activities for the environmental conservation in the construction project so called "environmental report" was published periodically. (d) The breeding situation of golden eagle and the activities for the environmental conservation were informed to mass media.

3.1.2.3 Activity after construction As a preservation measure, a marsh was reconstructed for both transplantation of the plants and habitat of the dragonfly in the planned soil disposal area. Eco-site monitoring was conducted every year, and habitats of precious animals and plants were confirmed in the reconstructed marsh.

\section{Method for environmental conservation measure under coexistence with natural environments}

Preservation of biodiversity should be required in any future hydro-power development. The following countermeasures were needed: preventive actions, environmental restoration, adaptive management, and monitoring and its evaluation. The two hydro-power projects introduced in the present paper show environmental conservation measures. The method for the environmental conservation measure under coexistence with natural environments was summarized as follows:

Basic-countermeasures: There are many unsolved questions as nature has a multifaceted and complicated system. The precise identification of the existing natural conditions was investigated before the activity of environmental measures, and design and countermeasures for the preventive conservation in the construction region were proposed under coexistence with natural environments.

Countermeasures for hardware activities: 1) In order to supply many unsolved questions in nature, experiment and measurement were conducted by cooperating with persons who have experts' knowledge in the construction project. 2) Adaptive management was applied under the uncertainly inherent in nature. Planning and its activity were conducted under precise prediction and its evaluation. In this case, a rule of countermeasure method was made under full dissemination to all construction workers. 3) Restoration for natural environment was conducted by utilizing the resilience of nature. Also, the construction workers' activities make restoring force emphasize.

Countermeasures for software activities: 1) The project manager must present an objective for environmental conservation to construction workers to obtain their understanding and cooperation, and the activities for the environmental measure were conducted routinely. 2) The project manager has a responsibility for both information disclosure through Home Page and the scientific and rational explanations of the project in order to obtain social agreement with persons concerned in the construction project. 3) Daily patrols were carried out in the construction region to confirm the status of environmental conservation measures. Also, prior prevention against the malfunction in environmental measures was 
performed, and the feedback to measures was conducted at the time of the influence discovery quickly again.

Eco-site monitoring activities: Eco-system monitoring during construction is essential to judge the effectiveness for the conservation measures and is important to execute hardware activities. Monitoring after construction and the evaluation for the measured data are required to confirm the status of restoration. Software activities constitute scientific ground to provide rational explanation for the persons concerned in the construction project.

A method of environmental conservation measures under coexistence with natural environments has been summarized as Figure 8 .

The techniques on basis two projects, Okinawa pilot seawater pumped-storage power plant construction project and Okutadami-Otori hydro-power plants expanding construction project might be a universal technique and might contribute to future hydro-power development and similar development.

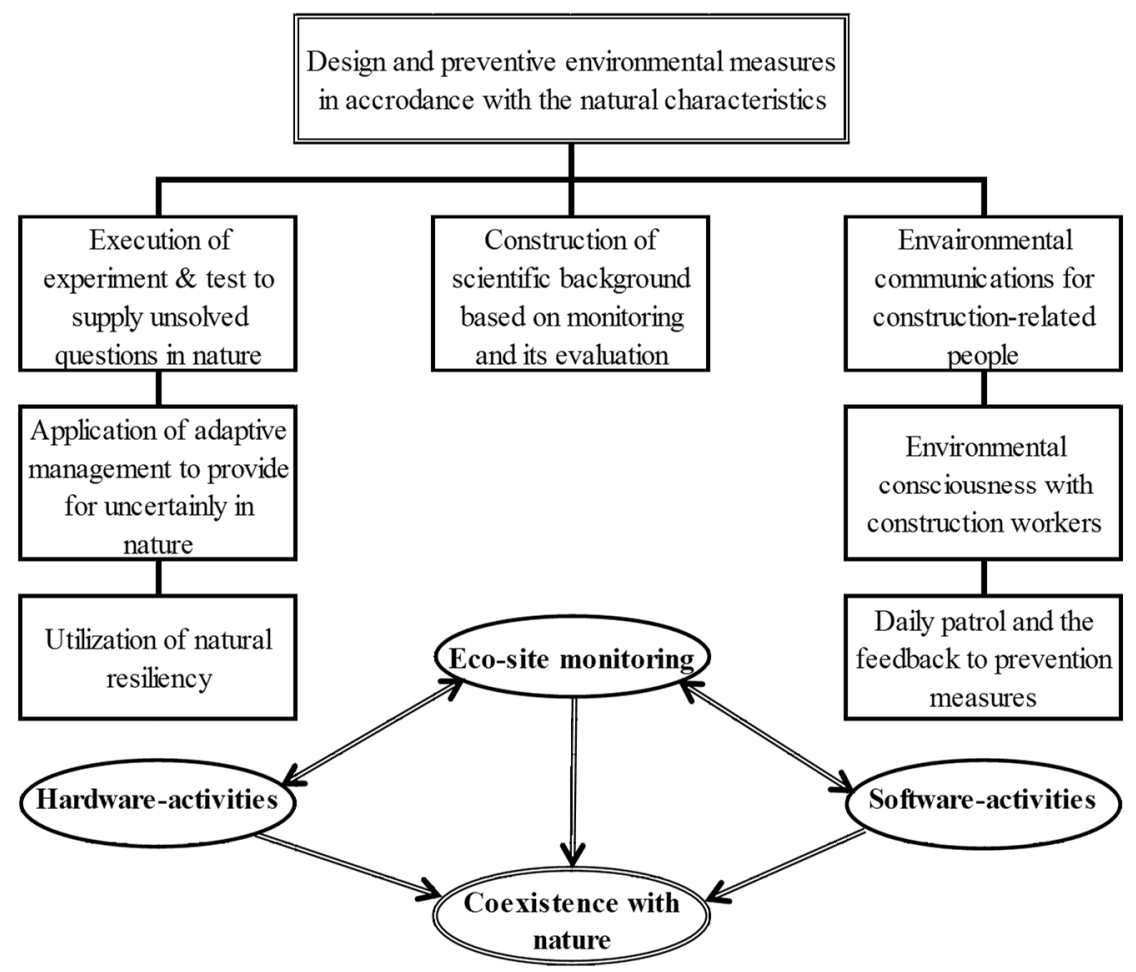

Figure 8: A method of environmental conservation measures under coexistence with natural environments. 


\section{Acknowledgements}

The authors highly appreciate every persons concerned in the construction projects: Okinawa pilot seawater pumped-storage power plant, and Okutadami and Otori hydro-power plants expanding conducted under their understanding and cooperation to conservation of natural environments. The success to harmonize two hydro-power plants developments with natural environments depends on their efforts. Also, the authors think a civil engineer has great mission to coexistence of natural environments and a development as necessity for human life.

\section{References}

[1] The Agency for Natural Resources and Energy at METI, 2014. The white paper on energy usage: pp. 215-218, 2015.

[2] The Federation of Electric Power Companies of Japan, 2011. Hand Book of Electric Power Industry. The Japan Electric Association: pp. 16-17, 2011.

[3] Komatsu, T., Sakata, J., and Takezawa, M., Environmental conservation measures for a construction of a power plant. Environmental Exposure and Health: WITPRESS, pp. 389-398, 2005.

[4] Electric Power Development Co. Ltd., The performance document of environmental conservation measures at the Okutadami \& Otori hydro-power plants expanding construction: 2004.

[5] The Agency for Natural Resources and Energy at METI and EPDC, 2003. Report of Seawater pumped-storage power plant demonstration test: pp. V-480-106, 111-115. 2004.

[6] Komatsu, T., Tobase, T., Hashimoto, O., and Nishikawa, K., A case study of adaptive management for the protection of juvenile golden eagle with respect to the construction of a hydro-power. Journal of JSCE: No. 811/VII, pp. 2335, 2006. 